\title{
Structural and Physical Properties of $\mathrm{Fe}_{2} \mathrm{O}_{3}-\mathrm{B}_{2} \mathrm{O}_{3}-\mathrm{V}_{2} \mathrm{O}_{5}$ Glasses
}

\author{
Virender Kundu, ${ }^{1}$ R. L. Dhiman, ${ }^{2}$ A. S. Maan, ${ }^{3}$ and D. R. Goyal ${ }^{3}$ \\ ${ }^{1}$ Department of Electronic Science, Kurukshetra University, Kurukshetra 136 119, India \\ ${ }^{2}$ Department of Applied Physics, S.D. College Ambala Cantt, Kurukshetra University, Ambala Cantt 133 001, India \\ ${ }^{3}$ Department of Physics, Maharshi Dayanand University, Rohtak 124 001, India
}

Correspondence should be addressed to Virender Kundu, vskundu_kuk@rediffmail.com

Received 23 May 2008; Revised 13 August 2008; Accepted 22 October 2008

Recommended by Gayanath Fernando

\begin{abstract}
The structural and physical properties of $x \mathrm{Fe}_{2} \mathrm{O}_{3}-(40-x) \mathrm{B}_{2} \mathrm{O}_{3}-60 \mathrm{~V}_{2} \mathrm{O}_{5}(0 \leq x \leq 20)$ glass system have been investigated. The samples were prepared by normal melt-quench technique. The structural changes were inferred by means of FTIR by monitoring the infrared (IR) spectra in the spectral range $600-4000 \mathrm{~cm}^{-1}$. The absence of boroxol ring $\left(806 \mathrm{~cm}^{-1}\right)$ in the present glass system suggested that these glasses consist of randomly connected $\mathrm{BO}_{3}$ and $\mathrm{BO}_{4}$ units. The conversion of $\mathrm{BO}_{3}$ to $\mathrm{BO}_{4}$ and $\mathrm{VO}_{5}$ to $\mathrm{VO}_{4}$ tetrahedra along with the formation of non-bridging oxygen's (NBOs) attached to boron and vanadium takes place in the glasses under investigation. The density and molar volume of the present glass system were found to depend on $\mathrm{Fe}_{2} \mathrm{O}_{3}$ content. DC conductivity of the glass system has been determined in the temperature range 310-500 K. It was found that the general behavior of electrical conductivity was similar for all glass compositions and found to increase with increasing iron content. The parameters such as activation energy, average separation between transition metal ions (TMIs), polaron radius, and so forth have been calculated in adiabatic region and are found consistent with Mott's model of phonon-assisted polaronic hopping.
\end{abstract}

Copyright ( $\odot 2008$ Virender Kundu et al. This is an open access article distributed under the Creative Commons Attribution License, which permits unrestricted use, distribution, and reproduction in any medium, provided the original work is properly cited.

\section{Introduction}

Borate glasses are generally insulating in nature, and the addition of transition metal oxide such as $\mathrm{Fe}_{2} \mathrm{O}_{3}$ and $\mathrm{V}_{2} \mathrm{O}_{5}$ makes these glasses semiconducting $[1,2]$. These semiconducting glasses have been extensively studied owing to their potential applications as optical and electrical memory switchings, cathode materials for making solid state devices, and optical fiber [3-5].

Structure of the borate glasses has been studied by various physical and chemical methods including Raman and Infrared spectroscopy, Brillouin experiments, NMR, and neutron scattering investigations [6-9]. Infrared (IR) spectroscopy is one of the important techniques which are used to study the local arrangement in inorganic glasses. In oxide glasses, $\mathrm{B}_{2} \mathrm{O}_{3}$ is a basic glass former because of its higher bond strength, lower cation size, smaller heat of fusion, and trivalancy of boron. In these glasses, boron $\left(\mathrm{B}^{3+}\right)$ ions are triangularly coordinated by oxygen to form glasses easily. The main structural units of vitreous $\mathrm{B}_{2} \mathrm{O}_{3}$ glasses are $\mathrm{BO}_{3}$ triangles forming three member (boroxol) rings connected by $\mathrm{B}-\mathrm{O}-\mathrm{B}$ linkage [10]. Boroxol ring is a highplanar ring with a bond length $1.36 \pm 0.005 \AA$, whereas the $\mathrm{B}-\mathrm{O}$ bond length for $\mathrm{BO}_{4}$ tetrahedra was observed to be $1.47 \pm 0.01 \AA[11]$. In IR spectra of borate glasses, the boroxol ring has its characteristic absorption at $806 \mathrm{~cm}^{-1}$ [12]. It has been observed that the structure of these glasses depends on the nature of the network formers as well as the network modifier. It has been reported that addition of a network modifier in borate glasses could produce the conversion of the triangular $\mathrm{BO}_{3}$ structural units to $\mathrm{BO}_{4}$ tetrahedra with coordination number of 4 , which are incorporated in more complex cyclic groups such as diborate, triborate, tetra or pentaborate, and the formation of $\mathrm{NBO}$ atoms $[8,9]$.

Transition-metal oxides (TMOs) glasses exhibit semiconducting properties due to the existence of TMIs in more than one valence state [1]. The electron-phonon interaction in these glasses is strong enough to form small polaron, and the electrical conduction process occurs by the hopping of small polarons between different valence states as proposed by Austin and Mott [2]. Hoping conduction in these glasses was generally known to be adiabatic for $\mathrm{V}_{2} \mathrm{O}_{5}$ content 
above $50 \mathrm{~mol} \%$ [13], and for $\mathrm{V}_{2} \mathrm{O}_{5}<50 \mathrm{~mol} \%$, conduction becomes non-adiabatic [14].

Sufficient work regarding the structural and physical properties of different oxide glasses having $\mathrm{TeO}_{2}$ and $\mathrm{P}_{2} \mathrm{O}_{5}$ as glass former has been reported [15-18], but relatively few work has been done on semiconducting oxide glasses (having Fe and $\mathrm{V}$ as TMIs) with $\mathrm{B}_{2} \mathrm{O}_{3}$ as a network former. The objective of present paper is to study the structural and physical properties of iron-boro-vandate glasses to shed some light on the role of the $\mathrm{Fe}_{2} \mathrm{O}_{3}$ in this glass system.

\section{Experimental Details}

\subsection{Sample Preparation}

Iron-doped vanadium borate glasses were prepared from analytical reagent grade powder of $\mathrm{Fe}_{2} \mathrm{O}_{3}, \mathrm{~V}_{2} \mathrm{O}_{5}$, and $\mathrm{H}_{3} \mathrm{BO}_{3}$ of high purity which are thoroughly mixed, in appropriate proportions. The batch materials were dry mixed and melted in porcelain crucibles placed in an electrically heated muffle furnace at $1473 \mathrm{~K}$ for about two hours, until a bubble-free liquid was formed. The melts were quickly cooled at room temperature by pouring and pressing between two stainless plates. As obtained glass samples were polished and finally cut into desired size $(\approx 10 \mathrm{~mm} \times 10 \mathrm{~mm} \times 1 \mathrm{~mm})$.

\subsection{FTIR Measurements}

The vibration spectra of the glass system were obtained at room temperature using FTIR spectrophotometer model $\mathrm{ABB}$ Bomen (MB-Series) in the range $600-4000 \mathrm{~cm}^{-1}$. The measurements were performed directly on glass pallets obtained as above.

\subsection{Density Measurements}

The density " $d$ " of the glasses was determined at room temperature using Archimedes principle with Xylene as an inert immersion liquid.

The molar volume $V_{M}$ of each glass sample was calculated using formula [19]

$$
V_{M}=\sum \frac{x_{i} M_{i}}{d}
$$

where $x_{i}$ is the molar fraction, and $M_{i}$ is the molecular weight of the $i$ th component.

\subsection{D.C. Conductivity Measurements}

The conductivity measurements were carried out by using Keithely electrometer (Model 617) in the temperature range of $310-500 \mathrm{~K}$. Silver paste electrodes were deposited on both faces of the polished samples. The absence of the barrier layers at the contacts was confirmed by linear $I-V$ characteristics.

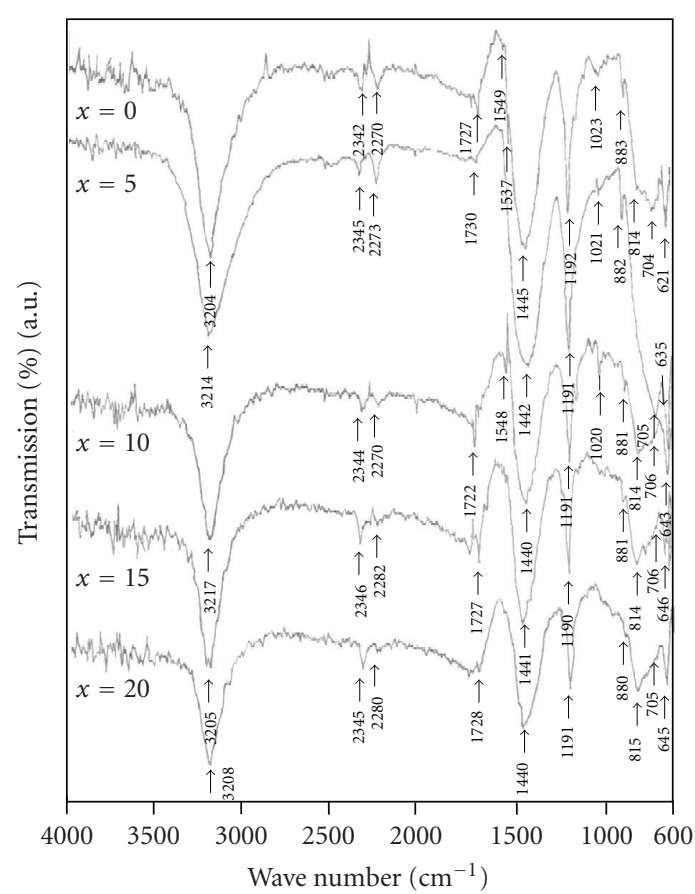

Figure 1: IR transmission spectra of $x \mathrm{Fe}_{2} \mathrm{O}_{3}-(40-x) \mathrm{B}_{2} \mathrm{O}_{3}-60 \mathrm{~V}_{2} \mathrm{O}_{5}$ glasses.

\section{Results and Discussion}

\subsection{FTIR Analysis}

The infrared spectra of $x \mathrm{Fe}_{2} \mathrm{O}_{3}-(40-x) \mathrm{B}_{2} \mathrm{O}_{3}-60 \mathrm{~V}_{2} \mathrm{O}_{5}$ glasses, with $x=0,5,10,15$, and $20 \mathrm{~mol} \%$, are shown in Figure 1. The vibrational modes of the borate network are seen to be mainly active in three infrared regions which are similar to those reported earlier $[20,21]$. The group of bands that occur at $1200-1600 \mathrm{~cm}^{-1}$ is due to the asymmetric stretching relaxation of the $\mathrm{B}-\mathrm{O}$ band of trigonal $\mathrm{BO}_{3}$ units. The second group of band lies between $800-1200 \mathrm{~cm}^{-1}$ and is due to the $\mathrm{B}-\mathrm{O}$ bond stretching of the tetrahedral $\mathrm{BO}_{4}$ units. The third group of absorption bands is observed around $700 \mathrm{~cm}^{-1}$ and is due to bending of $\mathrm{B}-\mathrm{O}-\mathrm{B}$ linkages in the borate network. Similar results have been reported for $\mathrm{V}_{2} \mathrm{O}_{5}-\mathrm{B}_{2} \mathrm{O}_{3}$ glasses $[22,23]$.

The absorption peaks assigned in IR spectra of glasses under study are listed in Table 1 . The absorption peak observed in all glass samples at $3204-3217 \mathrm{~cm}^{-1}$ is attributed to hydroxol or water groups [24] and it is due to hygroscopic nature of glass samples [25]. The peaks around 2270$2286 \mathrm{~cm}^{-1}$ and $2342-2345 \mathrm{~cm}^{-1}$ are attributed to $-\mathrm{OH}$ group [26]. The absorption peak around $1722-1730$ is due to $\mathrm{H}-\mathrm{O}-\mathrm{H}$ bending [22]. In the present glass system, the absence of peak at $806 \mathrm{~cm}^{-1}$ indicates the absence of boroxol ring formation [12], which suggests that the glass system under investigation consists of randomly connected $\mathrm{BO}_{3}$ and $\mathrm{BO}_{4}$ groups. The absorption peaks at 1192, 1445, 1537, and $1549 \mathrm{~cm}^{-1}[27,28]$ are related with the fundamental asymmetrical stretching vibration of the $\mathrm{B}-\mathrm{O}$ bond of the trigonal $\mathrm{BO}_{3}$ units. The absorption bands observed at 814 , 883 , and $1023 \mathrm{~cm}^{-1}[20,29]$ are assigned to the stretching 


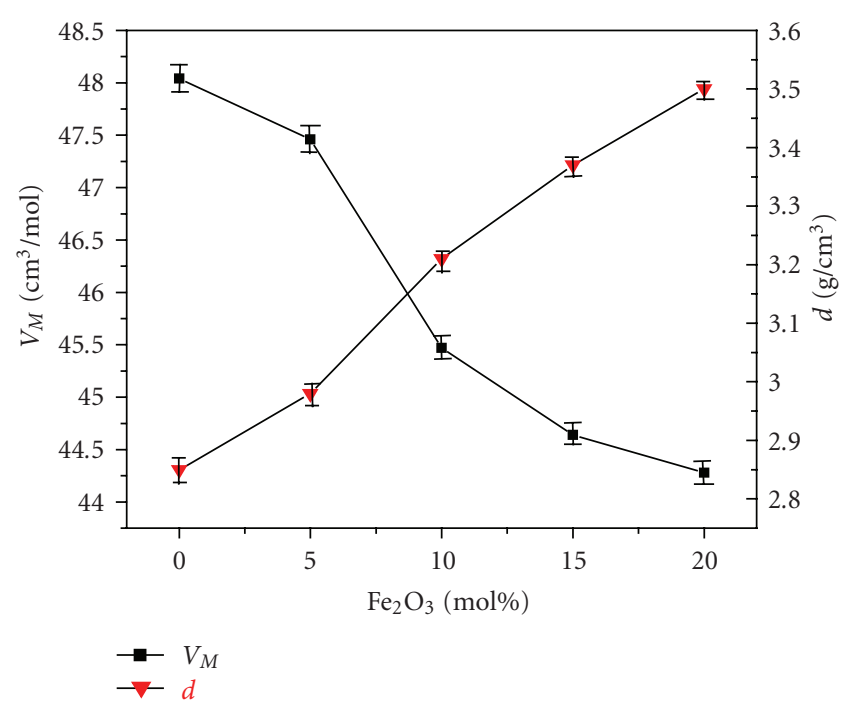

Figure 2: Variation of density and molar volume with $\mathrm{Fe}_{2} \mathrm{O}_{3}$ content.

vibrations of $\mathrm{B}-\mathrm{O}$ bond of tetrahedral $\mathrm{BO}_{4}$ units and are shifted toward lower wave numbers with increasing iron content. It is also observed (Figure 1) that on increasing $\mathrm{Fe}_{2} \mathrm{O}_{3}$ content, the absorption band at around $1445 \mathrm{~cm}^{-1}$ shifts toward lower wave number $\left(1445-1440 \mathrm{~cm}^{-1}\right)$ with noticeable decrease in intensity. In the present glass system, the shift of the vibrational band from higher to lower wave number is ascribed to the increase in the bond length of $\mathrm{B}-\mathrm{O}$ groups and the formation of $\mathrm{BO}_{4}$ units. The decrease in intensity of vibrational bands (for $x \leq 10 \mathrm{~mol} \%$ ) at 1445 and $1192 \mathrm{~cm}^{-1}$ and clear appearance of band in the lower region at $814 \mathrm{~cm}^{-1}$ suggest the formation of NBOs. A sharp absorption band observed at around $1192 \mathrm{~cm}^{-1}$ may be attributed to triangular $\mathrm{B}-\mathrm{O}$ stretching vibrations of $\mathrm{BO}_{3}$ units [27]. On increasing the $\mathrm{Fe}_{2} \mathrm{O}_{3}$ contents, the frequency of this band remains almost the same, revealing the strong appearance of the triangular borate units $\left(\mathrm{BO}_{3}\right)$. The absorption band observed at $621 \mathrm{~cm}^{-1}$ is due to the bending of O$\mathrm{B}-\mathrm{O}$ linkage [30]. The shifting of this band toward higher wave number $\left(621-646 \mathrm{~cm}^{-1}\right)$ with increasing $\mathrm{Fe}_{2} \mathrm{O}_{3}$ content indicates the formation of $\mathrm{FeO}_{4}$ group [30]. This possibility is more in the borate glasses in which boroxol rings are absent. The absorption peak observed at $704 \mathrm{~cm}^{-1}$ is assigned to $\mathrm{B}-\mathrm{O}-\mathrm{B}$ bending vibration in borate network [31]. At low concentration of $\mathrm{Fe}_{2} \mathrm{O}_{3}$, a weak absorption band observed at $814 \mathrm{~cm}^{-1}$ originates from stretching vibration of $\mathrm{V}-\mathrm{O}-\mathrm{V}$ bridges [32] and becomes slight intense as the concentration of $\mathrm{Fe}_{2} \mathrm{O}_{3}$ increases. The weak absorption band appearing in all the samples at $\approx 883 \mathrm{~cm}^{-1}$ is due to $\mathrm{V}_{2} \mathrm{O}_{5}$ content. The shoulder at $1023 \mathrm{~cm}^{-1}$ can be referred to stretching vibrations of $\mathrm{BO}_{4}$ tetrahedra and is also due to higher content of $\mathrm{V}_{2} \mathrm{O}_{5}$ in the glass system. It has been reported that the $\mathrm{V}_{2} \mathrm{O}_{5}$ structure is built up by deformed $\mathrm{VO}_{5}$ trigonal bonded zigzag chains. Each $\mathrm{VO}_{5}$ group contains a short $\mathrm{V}=\mathrm{O}$ bond (Vanadyl group), which shows its characteristic vibration band at around $1023 \mathrm{~cm}^{-1}$ [33]. The appearance of this frequency band at $1020 \mathrm{~cm}^{-1}$ at $x=10(\mathrm{~mol} \%)$ and the clear separation of the peak at $814 \mathrm{~cm}^{-1}$ on increasing $\mathrm{Fe}_{2} \mathrm{O}_{3}$ contents suggest that this absorption is not only due to the presence of nonbridging $\mathrm{V}-\mathrm{O}^{-1}$ and $\mathrm{V}=\mathrm{O}$ bond, but also due to the presence of $\mathrm{BO}_{4}$ tetrahedra. Similar results have also been observed in potasium-boro-vanadate-iron glasses [34]. From Figure 1, it can be clearly inferred that a weak absorption band corresponding to $814 \mathrm{~cm}^{-1}$ appears for low concentration of $\mathrm{Fe}_{2} \mathrm{O}_{3}$. This peak, however, disappears as the concentration of $\mathrm{Fe}_{2} \mathrm{O}_{3}$ increases $(x=5 \mathrm{~mol} \%)$ and with further increase in $\mathrm{Fe}_{2} \mathrm{O}_{3}$ content $(x=10 \mathrm{~mol} \%)$, the increase in intensity of this peak indicates that the $\mathrm{Fe}_{2} \mathrm{O}_{3}$ acts as a glass modifier. The intensity of $\mathrm{BO}_{3}$ structural units decreases on further increases of $\mathrm{Fe}_{2} \mathrm{O}_{3}$ contents, and clear appearance of peaks $\left(\approx 814 \mathrm{~cm}^{-1}\right)$ in the lower region suggests that some $\mathrm{BO}_{3}$ structural units are converted into some $\mathrm{BO}_{4}$ tetrahedral units, which results in the formation of NBOs. On further addition of $\mathrm{Fe}_{2} \mathrm{O}_{3}$ contents (15-20 mol\%), the absorption bands observed in the lower region, that is, at 1190, 881, 814, 706 , and $646 \mathrm{~cm}^{-1}$ remain almost unaffected, however, their intensities changes which indicate that $\mathrm{Fe}_{2} \mathrm{O}_{3}$ also acts as a glass former. These observations suggest that at low concentration $(x \leq 10 \mathrm{~mol} \%), \mathrm{Fe}_{2} \mathrm{O}_{3}$ acts as a glass modifier and at high concentration $(x=15-20 \mathrm{~mol} \%), \mathrm{Fe}_{2} \mathrm{O}_{3}$ acts as a glass former. Therefore, in the present glass system, $\mathrm{Fe}_{2} \mathrm{O}_{3}$ acts both, as a glass modifier as well as a glass former. The results obtained are well consistent with already reported result [26].

\subsection{Density and Molar Volume}

The determined values of density " $d$ " and molar volume " $V_{M}$ " of the glass samples are presented in Table 3. In general, the density of glass system is explained in terms of a competition between the masses and sizes of the various structural units present in glass. In other words, the density is related to how tightly the ions and ionic groups are packed together in the structure. The variation of density as a function of glass composition $(x)$ is shown in Figure 2. It is observed that the density increases gradually with the increase in $\mathrm{Fe}_{2} \mathrm{O}_{3}$ content in the present glass system. The relationship between density and glass composition $(x)$ can be explained in terms of an apparent volume $V_{M}$ occupied by $1 \mathrm{gm}$ atom of oxygen. The value of $V_{M}$ has been calculated from the density and composition using the formula reported earlier [19], and its composition dependence is shown in Figure 2. It is observed that molar volume decreases monotonically with the increase of $\mathrm{Fe}_{2} \mathrm{O}_{3}$ content which indicates that the topology of the network is significantly changed with composition. On the other hand, these trends can be explained rather simply due to the replacement of a lighter cation (B) by a heavier one (Fe). As observed in IR spectra, the addition of $\mathrm{Fe}_{2} \mathrm{O}_{3}$ causes increase in NBOs, which in turn randomizes the structure and, therefore, glass structure becomes relatively more open. These results are found consistent with the results reported earlier $[35,36]$.

\subsection{Conductivity}

The temperature dependence of $\mathrm{dc}$ conductivity " $\sigma$ " for the different glass compositions is shown in Figure 3. It is 
TABLE 1: Peak frequencies from IR spectra for $x \mathrm{Fe}_{2} \mathrm{O}_{3}-(40-x) \mathrm{B}_{2} \mathrm{O}_{3}-60 \mathrm{~V}_{2} \mathrm{O}_{5}$ glass system.

\begin{tabular}{|c|c|c|c|c|c|c|c|c|c|c|c|c|c|}
\hline \multirow{3}{*}{$\begin{array}{l}x \\
(\mathrm{~mol} \%) \\
0\end{array}$} & \multicolumn{13}{|c|}{ Peak position $\left(\mathrm{cm}^{-1}\right)$} \\
\hline & \multirow{2}{*}{$\frac{\mathrm{O}-\mathrm{B}-\mathrm{O}}{621}$} & \multirow{2}{*}{$\frac{\text { B-O-B }}{704}$} & \multicolumn{3}{|c|}{$\mathrm{BO}_{4}$} & \multicolumn{4}{|c|}{$\mathrm{BO}_{3}$} & \multicolumn{4}{|c|}{$\mathrm{OH}^{-1}$ group } \\
\hline & & & 814 & 883 & 1023 & 1192 & 1445 & 1537 & 1549 & 1727 & 2270 & 2342 & 3204 \\
\hline 5 & 635 & 705 & - & 882 & 1021 & 1191 & 1442 & - & - & 1730 & 2273 & 2345 & 3214 \\
\hline 10 & 643 & 706 & 814 & 881 & 1020 & 1191 & 1440 & - & 1548 & 1722 & 2270 & 2344 & 3217 \\
\hline 15 & 646 & 706 & 814 & 881 & - & 1190 & 1441 & - & - & 1727 & 2282 & 2346 & 3205 \\
\hline 20 & 645 & 705 & 815 & 880 & - & 1191 & 1440 & - & - & 1728 & 2286 & 2345 & 3208 \\
\hline
\end{tabular}

TABLE 2: Electrical conductivity at different temperatures and the prefactor of Mott-Austin formula of $x \mathrm{Fe}_{2} \mathrm{O}_{3}-(40-x) \mathrm{B}_{2} \mathrm{O}_{3}-60 \mathrm{~V}_{2} \mathrm{O}_{5}$ glasses.

\begin{tabular}{|c|c|c|c|c|}
\hline$x(\mathrm{~mol} \%)$ & $\sigma_{320 \mathrm{~K}}(\Omega \mathrm{m})^{-1}$ & $\sigma_{400 \mathrm{~K}}(\Omega \mathrm{m})^{-1}$ & $\sigma_{500 \mathrm{~K}}(\Omega \mathrm{m})^{-1}$ & $\log \sigma_{0}$ \\
\hline 0 & $0.313 \times 10^{-4}$ & $5.435 \times 10^{-4}$ & $7.945 \times 10^{-3}$ & 2.673 \\
\hline 5 & $1.600 \times 10^{-4}$ & $1.783 \times 10^{-3}$ & $1.987 \times 10^{-2}$ & 2.793 \\
\hline 10 & $5.817 \times 10^{-4}$ & $7.705 \times 10^{-3}$ & $4.339 \times 10^{-2}$ & 1.750 \\
\hline 15 & $2.680 \times 10^{-3}$ & $1.794 \times 10^{-2}$ & $8.853 \times 10^{-2}$ & 1.581 \\
\hline 20 & $8.220 \times 10^{-3}$ & $4.194 \times 10^{-2}$ & $14.73 \times 10^{-2}$ & 1.450 \\
\hline
\end{tabular}

TABLE 3: Chemical composition and physical properties of $x \mathrm{Fe}_{2} \mathrm{O}_{3}$ $(40-x) \mathrm{B}_{2} \mathrm{O}_{3}-60 \mathrm{~V}_{2} \mathrm{O}_{5}$ glasses.

\begin{tabular}{llll}
\hline$x(\mathrm{~mol} \%)$ & $\begin{array}{l}\text { Molar volume } \\
V_{M}\left(\mathrm{~cm}^{3} / \mathrm{mol}\right)\end{array}$ & $\begin{array}{l}\text { Density } \\
d\left(\mathrm{~g} / \mathrm{cm}^{3}\right)\end{array}$ & $W(\mathrm{eV})$ \\
\hline 0 & 48.04 & 2.85 & 0.427 \\
5 & 47.46 & 2.98 & 0.361 \\
10 & 45.47 & 3.21 & 0.329 \\
15 & 44.64 & 3.37 & 0.266 \\
20 & 44.28 & 3.50 & 0.220 \\
\hline
\end{tabular}

observed that conductivity increases smoothly with increasing temperature, indicating temperature dependence activation energy " $W$ " which is characteristic of small polaron hopping ( $\mathrm{SPH}$ ) conduction mechanism in TMO glasses [37]. As shown in Figure 3, the logarithmic conductivity in the temperature range $(310-500 \mathrm{~K})$ exhibits a linear dependence on reciprocal temperature. The composition dependence of dc conductivity at particular temperature (Figure 4) indicates that the conductivity increases with increasing $\mathrm{Fe}_{2} \mathrm{O}_{3}$ content. The activation energy calculated from the slop of the graphs (Figure 3 ) is listed in Table 3. It is clear from Figure 5 that the activation energy decreases with increasing $\mathrm{Fe}_{2} \mathrm{O}_{3}$ content. The composition dependence of dc conductivity at $400 \mathrm{~K}$ (Figure 4) and activation energy (Figure 5) indicate that the variation of " $\sigma$ " as well as " $W$ " with composition is much faster for the present glass system than those for the traditional vandate glasses. It is observed that as the concentration of $\mathrm{Fe}_{2} \mathrm{O}_{3}$ increases, the activation of electrical conduction decreases and electrical conductivity increases. The low value of activation energy and high value of electrical conductivity are similar to those of $\mathrm{V}_{2} \mathrm{O}_{5}$ $\mathrm{BaO}-\mathrm{B}_{2} \mathrm{O}_{3}$ glasses [38]. The change in conductivity and activation energy may help to detect the structural changes as a consequence of increasing of $\mathrm{Fe}_{2} \mathrm{O}_{3}$ content and decreasing of boron oxide content. Generally, it is known that addition



Figure 3: Variation of $\log \sigma$ versus $1000 / T\left(\mathrm{~K}^{-1}\right)$ for studied glasses.

of $\mathrm{Fe}_{2} \mathrm{O}_{3}$ in borate glasses increases the conductivity as result of increasing of NBO ions [39]. It is clear from Figures 4 and 5 that the magnitude of conductivity is higher for those compositions which have lower activation energy. This result is in consistent with the small polaron hopping theory [40]. According to this theory, the conduction process at higher temperature is considered in terms of optical phonon assisted hopping of small polaron between localized states. The dc conductivity in adiabatic region is given by

$$
\sigma=\sigma_{0} \exp \left(-\frac{W}{k T}\right)
$$


TABLE 4: Hopping parameters of $x \mathrm{Fe}_{2} \mathrm{O}_{3}-(40-x) \mathrm{B}_{2} \mathrm{O}_{3}-60 \mathrm{~V}_{2} \mathrm{O}_{5}$ glasses.

\begin{tabular}{lccccc}
\hline$x(\mathrm{~mol} \%)$ & $n_{\mathrm{Fe}_{2} \mathrm{O}_{3}}\left(\mathrm{~cm}^{-3}\right)$ & $n_{\mathrm{V}_{2} \mathrm{O}_{5}}\left(\mathrm{~cm}^{-3}\right)$ & $N\left(\mathrm{~cm}^{-3}\right)$ & $R(\mathrm{~nm})$ & 0.3212 \\
\hline 0 & $0 \times 10^{23}$ & $0.1131 \times 10^{23}$ & $0.1131 \times 10^{23}$ & 0.3074 \\
5 & $0.0112 \times 10^{23}$ & $0.1183 \times 10^{23}$ & $0.129 \times 10^{23}$ & 0.179 \\
10 & $0.024 \times 10^{23}$ & $0.1274 \times 10^{23}$ & $0.151 \times 10^{23}$ & 0.2917 \\
15 & $0.038 \times 10^{23}$ & $0.1337 \times 10^{23}$ & $0.171 \times 10^{23}$ & 0.2799 \\
20 & $0.052 \times 10^{23}$ & $0.1389 \times 10^{23}$ & $0.191 \times 10^{23}$ & 0.2697 \\
\hline
\end{tabular}

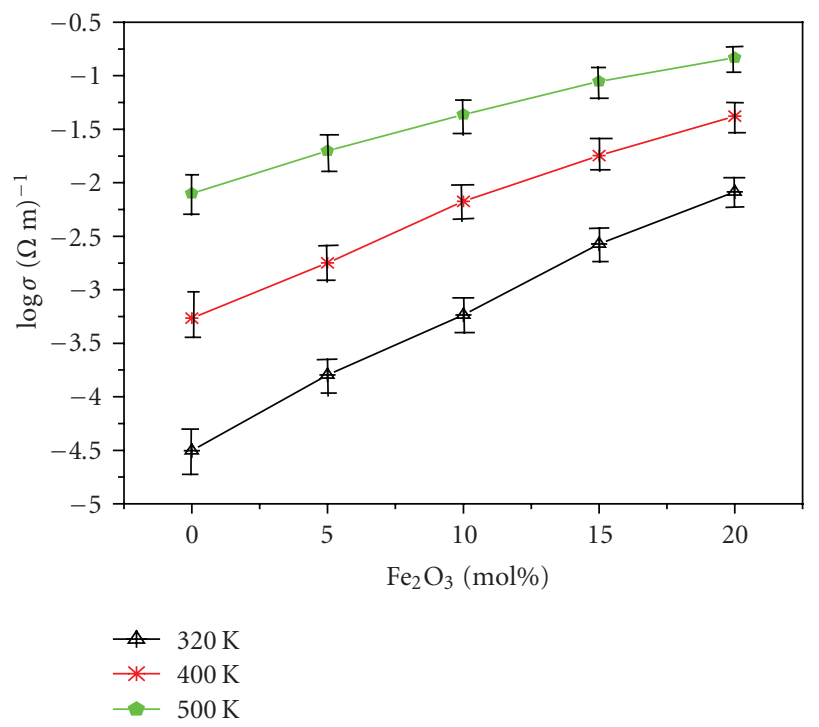

Figure 4: Effect of $\mathrm{Fe}_{2} \mathrm{O}_{3}$ content on dc conductivity at different temperatures.

where $\sigma_{0}$ is a pre-exponentional factor, $W$ is the activation energy, $k$ is Boltzmann constant, and $T$ is temperature in Kelvin. The values of $\log \sigma_{0}$ were determined from the intercept of the conductivity versus temperature curve (Figure 3). The observed values of $\log \sigma_{0}$ are found to be independent of $\mathrm{Fe}_{2} \mathrm{O}_{3}$ content (Figure 5) which confirms the adiabatic SPH for the present glass system. The present glass system consists of two types of TMIs, that is, Fe and V. The density " $n$ " of respective ions was calculated (in order to confirm the relation between the activation energy $W$ and mean distance $R$ ) using the formula [14]:

$$
n=2\left[\left(\frac{d W_{t}}{M_{w}}\right) N_{A}\right]
$$

where $d, N_{A}, W_{t}$, and $M_{w}$ are the measured density of the sample, Avogadro's number, weight fraction, and molecular weight of the respective ions $(\mathrm{Fe} \& \mathrm{~V})$, respectively. The calculated values of iron and vanadium ions are listed in Table 4 . The average distance " $R$ " between the transition ions (assuming homogenous distribution of transition ion in glass volume) was calculated as follows:

$$
R=\left(\frac{1}{N}\right)^{1 / 3},
$$

where " $N$ " is the concentration of total TMIs $\left(n_{\mathrm{Fe}_{2} \mathrm{O}_{3}}+n_{\mathrm{V}_{2} \mathrm{O}_{5}}\right)$.



Figure 5: Effect of $\mathrm{Fe}_{2} \mathrm{O}_{3}$ content on activation energy $W$ and preexponential factor $\log \sigma_{0}$.

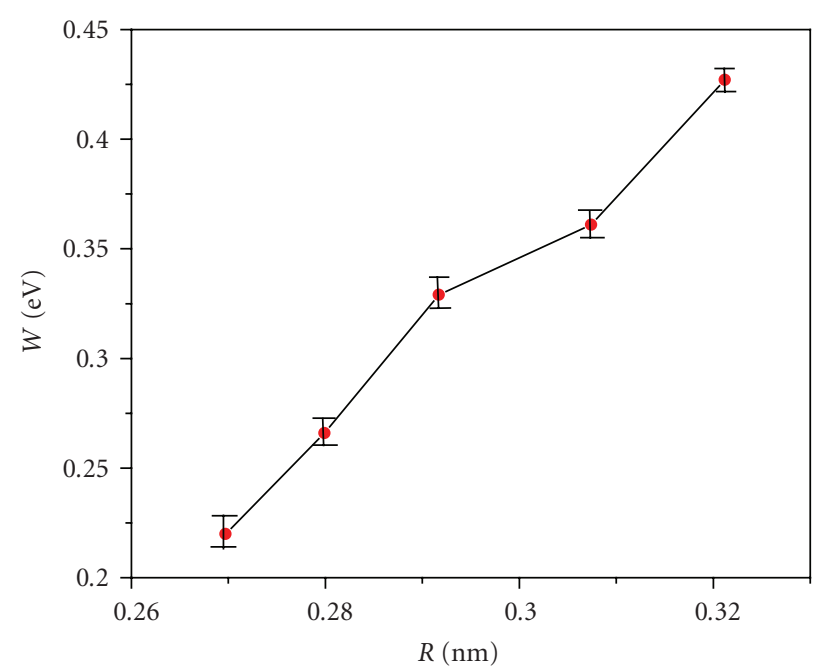

FIgURE 6: Variation of activation energy $W$ with average ion separation $R$.

The small polaron radii " $r_{p}$ " for the iron and vanadium ions have been calculated using [41]

$$
r_{p}=\frac{1}{2}\left(\frac{\pi}{6 N}\right)^{1 / 3} \text {. }
$$






FIgURE 7: Variation of small polaron radius with iron content.

The calculated values of $N, R$, and $r_{p}$ are tabulated in Table 4 . The variation of activation energy $W$ with average distance $R$, as shown in Figure 6, suggests that there is a prominent positive correlation between activation energy and average site separation. It is evident from Figure 7 that the small polaron (SP) radius decreases with the increase in Fe-ion concentration. From the above observations, it is concluded that on addition of $\mathrm{Fe}_{2} \mathrm{O}_{3}$, conductivity increases, while the activation energy decreases due to the decrease in respective ion separation. These results are in good agreement with those reported by El-Desoky [36]. However, in the present investigation for sample $x=10 \mathrm{~mol} \%$ of $\mathrm{Fe}_{2} \mathrm{O}_{3}$, there are some minor changes observed in the density and electrical parameters as compared to our earlier investigation [42]. These changes may be attributed to difference in sample preparation conditions [11].

\section{Conclusion}

The structural and physical properties of $x \mathrm{Fe}_{2} \mathrm{O}_{3}-(40-x)$ $\mathrm{B}_{2} \mathrm{O}_{3}-60 \mathrm{~V}_{2} \mathrm{O}_{5}$ glass system, with $0 \leq x \leq 20$ (mol\%), have been studied. No boroxol ring formation was observed in the structure of these glasses which suggest that glasses under study consist of randomly connected $\mathrm{BO}_{3}$ and $\mathrm{BO}_{4}$ groups. Addition of $\mathrm{Fe}_{2} \mathrm{O}_{3}$ produces NBOs in borate as well as in Vandate glass network along with the formation of $\mathrm{VO}_{4}$ groups. The IR spectra of the present glass system indicate that $\mathrm{Fe}_{2} \mathrm{O}_{3}$ acts both, as a glass modifier ( $\left.x \leq 10 \mathrm{~mol} \%\right)$ as well as a glass former $(x=15-20 \mathrm{~mol} \%)$. The density of all the glass samples increases with $\mathrm{Fe}_{2} \mathrm{O}_{3}$ content as a result of the increase in NBOs due to the conversion of trigonal $\mathrm{BO}_{3}$ structural units into $\mathrm{BO}_{4}$ tetrahedral unit. In the temperature range $310-500 \mathrm{~K}$, the variation of $\log \sigma$ with $T^{-1}$ is approximately linear. It was observed that the dc conductivity increases with increasing iron content, and ranges from $5.435 \times 10^{-4}$ to $4.194 \times 10^{-2}(\Omega \mathrm{m})^{-1}$ at $400 \mathrm{~K}$. The conduction in the present glass system was confirmed to be a result of primarily adiabatic hopping of small polarons between TMIs.

\section{References}

[1] N. F. Mott, "Conduction in glasses containing transition metal ions," Journal of Non-Crystalline Solids, vol. 1, no. 1, pp. 1-17, 1968.

[2] I. G. Austin and N. F. Mott, "Polarons in crystalline and noncrystalline materials," Advances in Physics, vol. 18, no. 71, pp. 41-102, 1969.

[3] M. Regan and C. F. Drake, "High current glass switches," Materials Research Bulletin, vol. 6, no. 6, pp. 487-490, 1971.

[4] M. Nagaswa and H. Watanabe, UK Patent No. 1358930(1971).

[5] R. A. Montani, M. Lévy, and J. L. Souquet, "An electrothermal model for high-field conduction and switching phenomena in $\mathrm{Te}_{2} \mathrm{O}_{2}-\mathrm{V}_{2} \mathrm{O}_{5}$ glasses," Journal of Non-Crystalline Solids, vol. 149, no. 3, pp. 249-256, 1992.

[6] M. Iron, M. Couzi, A. levasseur, J. M. Reau, and J. C. Brethous, "An infrared and Raman study of new lonic-conductor lithium glasses," Journal of Solid State Chemistry, vol. 31, no. 3, pp. 285-294, 1980.

[7] F. L. Galeener, G. Lucovsky, and J. C. Mikkelsen Jr., "Vibrational spectra and the structure of pure vitreous $\mathrm{B}_{2} \mathrm{O}_{3}$," Physical Review B, vol. 22, no. 8, pp. 3983-3990, 1980.

[8] J. Lorösch, M. Couzi, J. Pelous, R. Vacher, and A. Levasseur, "Brillouin and raman scattering study of borate glasses," Journal of Non-Crystalline Solids, vol. 69, no. 1, pp. 1-25, 1984.

[9] G. E. Jellison Jr. and P. J. Bray, "A structural interpretation of $\mathrm{B}^{10}$ and $\mathrm{B}^{11}$ NMR spectra in sodium borate glasses," Journal of Non-Crystalline Solids, vol. 29, no. 2, pp. 187-206, 1979.

[10] Y. Ito, K. Miyauchi, and T. Oi, "Ionic conductivity of $\mathrm{Li}_{2} \mathrm{O}-$ $\mathrm{B}_{2} \mathrm{O}_{3}$ thin films," Journal of Non-Crystalline Solids, vol. 57, no. 3, pp. 389-400, 1983.

[11] W. Soppe, C. van der Marel, W. F. van Gunsteren, and H. W. den Hartog, "New insights into the structure of $\mathrm{B}_{2} \mathrm{O}_{3}$ glass," Journal of Non-Crystalline Solids, vol. 103, no. 2-3, pp. 201209, 1988.

[12] A. A. Alemi, H. Sedghi, A. R. Mirmohseni, and V. Golsanamlu, "Synthesis and characterization of cadmium doped leadborate glasses," Bulletin of Materials Science, vol. 29, no. 1, pp. 55-58, 2006.

[13] K. Sega, Y. Kuroda, and H. Sakata, "D.c. conductivity of $\mathrm{V}_{2} \mathrm{O}_{5}$ $\mathrm{MnO}-\mathrm{TeO}_{2}$ glasses," Journal of Materials Science, vol. 33, no. 5, pp. 1303-1308, 1998.

[14] H. Mori, H. Matsuno, and H. Sakata, "Small polaron hopping conduction in $\mathrm{V}_{2} \mathrm{O}_{5}-\mathrm{Sb}-\mathrm{TeO}_{2}$ glasses," Journal of NonCrystalline Solids, vol. 276, no. 1, pp. 78-94, 2000.

[15] M.M. El-Desoky and M. S. Al-Assiri, "Structural and Polaronic transport properties of semiconducting $\mathrm{CuO}-\mathrm{V}_{2} \mathrm{O}_{5}$ $\mathrm{TeO}_{2}$ glasses," Materials Science and Engineering B, vol. 137, no. 1-3, pp. 237-246, 2007.

[16] M. Pal, K. Hirota, Y. Tsujigami, and H. Sakata, "Structural and electrical properties of $\mathrm{MoO}_{3}-\mathrm{TeO}_{2}$ glasses," Journal of Physics $D$, vol. 34, no. 4, pp. 459-464, 2001.

[17] A. Moguš-Milanković, V. Ličina, S. T. Reis, and D. E. Day, "Electronic relaxation in zinc iron phosphate glasses," Journal of Non-Crystalline Solids, vol. 353, no. 27, pp. 2659-2666, 2007.

[18] A. Moguš-Milanković, A. Šantić, M. Karabulut, and D. E. Day, "Study of electrical properties of $\mathrm{MoO}_{3}-\mathrm{Fe}_{2} \mathrm{O}_{3}-\mathrm{P}_{2} \mathrm{O}_{5}$ and $\mathrm{SrO}$ $\mathrm{Fe}_{2} \mathrm{O}_{3}-\mathrm{P}_{2} \mathrm{O}_{5}$ glasses by impedance spectroscopy. II," Journal of Non-Crystalline Solids, vol. 330, no. 1-3, pp. 128-141, 2003. 
[19] B. N. Meera and J. Ramakrishna, "Raman spectral studies of borate glasses," Journal of Non-Crystalline Solids, vol. 159, no. 1-2, pp. 1-21, 1993.

[20] E. I. Kamitsos, M. A. Karakassides, and G. D. Chryssikos, "Vibrational spectra of magnesium-sodium-borate glasses. 2. Raman and mid-infrared investigation of the network structure," Journal of Physical Chemistry, vol. 91, no. 5, pp. 1073-1079, 1987.

[21] S. G. Motke, S. P. Yawale, and S. S. Yawale, "Infrared spectra of zinc doped lead borate glasses," Bulletin of Materials Science, vol. 25, no. 1, pp. 75-78, 2002.

[22] B. K. Sharma and D. C. Dube, "Preparation and characterisation of $\mathrm{V}_{2} \mathrm{O}_{5}-\mathrm{B}_{2} \mathrm{O}_{3}$ glasses," Journal of Non-Crystalline Solids, vol. 65 , no. 1, pp. 39-51, 1984.

[23] A. Abd El-Moneim, "DTA and IR absorption spectra of vanadium tellurite glasses," Materials Chemistry and Physics, vol. 73, no. 2-3, pp. 318-322, 2002.

[24] R. A. Adams and R. W. Douglas, "Infrared studies on various samples of fused silica with special reference to the bands due to water," Journal of the Society of Glass Technology, vol. 43, pp. $147-158,1959$.

[25] N. F. Borrrlli and G.-J. Su, Physics and Chemistry of Glasses, vol. 4, p. 206, 1963.

[26] D. Mmaniu, T. Iliescu, I. Ardelean, L. Bratu, and C. Dem, Studia Universitatis Babes- Bolyai, Physica, 2001.

[27] Y. D. Yiannopoulos, G. D. Chryssikos, and E. I. Kamitsos, "Structure and properties of alkaline earth borate glasses," Physics and Chemistry of Glasses, vol. 42, no. 3, pp. 164-172, 2001.

[28] E. E. Horopanitis, G. Perentzis, A. Beck, L. Guczi, G. Peto, and L. Papadimitriou, "Correlation between structural and electrical properties of heavily lithiated boron oxide solid electrolytes," Journal of Non-Crystalline Solids, vol. 354, no. 29, pp. 374-379, 2008.

[29] V. Dimitrov, Y. Dimitriev, and A. Montenero, "IR spectra and structure of $\mathrm{V}_{2} \mathrm{O}_{5}-\mathrm{GeO}_{2}-\mathrm{Bi}_{2} \mathrm{O}_{3}$ glasses," Journal of NonCrystalline Solids, vol. 180, no. 1, pp. 51-57, 1994.

[30] R. Lal and N. D. Sharma, "Infrared spectroscopic study of zinc doped iron borate glasses," Indian Journal of Pure \& Applied Physics, vol. 43, no. 11, pp. 828-832, 2005.

[31] F. A. Khalifa, H. A. El Batal, and A. Azooz, "Infrared absorption spectra of gamma irradiated glasses of the system $\mathrm{Li}_{2} \mathrm{O}-\mathrm{B}_{2} \mathrm{O}_{3}-\mathrm{Al}_{2} \mathrm{O}_{3}$," Indian Journal of Pure and Applied Physics, vol. 36, no. 6, pp. 314-318, 1998.

[32] K. Morinaga, Y. Suginohara, and Y. Yanagase, "Infrared absorption spectra of silicate glasses containing $\mathrm{Fe}_{2} \mathrm{O}_{3}$," Journal of the Japan Institute of Metals, vol. 40, no. 8, pp. 775-780, 1976.

[33] R. Lewandowska, K. Krasowski, R. Bacewicz, and J. E. Garbarczyk, "Studies of silver-vanadate superionic glasses using Raman spectroscopy," Solid State Ionics, vol. 119, no. 1, pp. 229-234, 1999.

[34] H. G. Bachman, F. R. Ahmed, and W. H. Barnes, Zeitschrift für Kristallographie, vol. 115, p. 110, 1961.

[35] V. Dimitrov, Y. Dimitriev, and V. Mihailova, "IR-spectral investigation of the structure of glasses in the $\mathrm{Fe}_{2} \mathrm{O}_{3}-\mathrm{V}_{2} \mathrm{O}_{5}$ system," Monatshefte für Chemie, vol. 114, no. 6-7, pp. 669674, 1983.

[36] M. M. El-Desoky, "DC conductivity and hopping mechanism in $\mathrm{V}_{2} \mathrm{O}_{5}-\mathrm{B}_{2} \mathrm{O}_{3}-\mathrm{BaO}$ glasses," Physica Status Solidi A, vol. 195, no. 2, pp. 422-428, 2003.

[37] M. M. El-Desoky and A. Al-Shahrani, "Iron doping of semiconducting bismuth alkali borate glasses," Physica B, vol. 383, no. 2, pp. 163-170, 2006.
[38] V. K. Dhawan, A. Mansingh, and M. Sayer, "DC conduvtivity of $\mathrm{V}_{2} \mathrm{O}_{5}-\mathrm{TeO}_{2}$ glasses," Journal of Non-Crystalline Solids, vol. 51, no. 1, pp. 87-103, 1982.

[39] H. Doweidar, A. Megahed, and I. A. Gohar, "Mixed ionicelectronic conduction in sodium borate glasses with low $\mathrm{V}_{2} \mathrm{O}_{5}$ content," Journal of Physics D, vol. 19, no. 10, pp. 1939-1946, 1986.

[40] I. G. Austin and N. F. Mott, "Polarons in crystalline and noncrystalline materials," Advances in Physics, vol. 18, no. 71, pp. 41-102, 1969.

[41] V. N. Bogomolov, E. K. Kudinev, and U. N. Firsov, Soviet Physics-Solid State, vol. 9, p. 2502, 1968.

[42] V. Kundu, R. L. Dhiman, D. R. Goyal, and A. S. Maan, Optoelectronics and Advanced Materials-Rapid Communications, vol. 27, p. 428, 2008. 



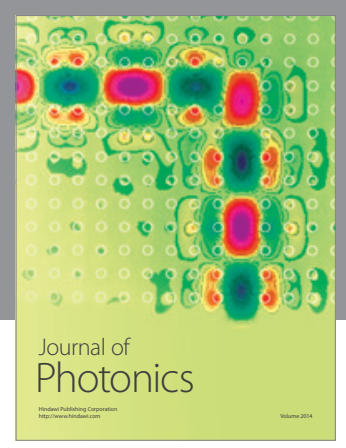

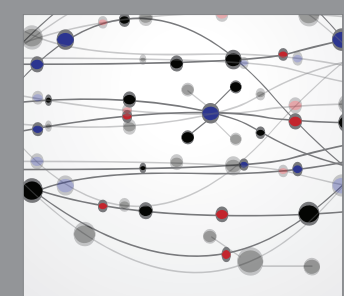

The Scientific World Journal


Submit your manuscripts at

http://www.hindawi.com
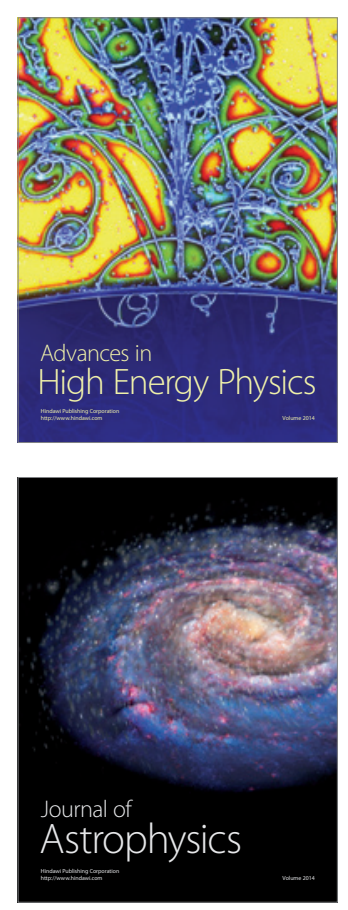
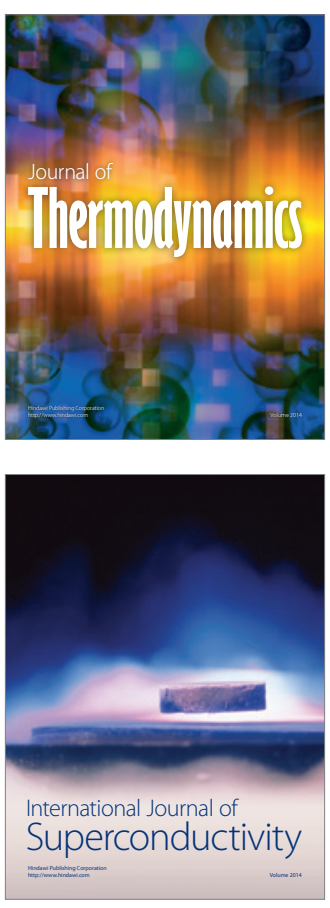
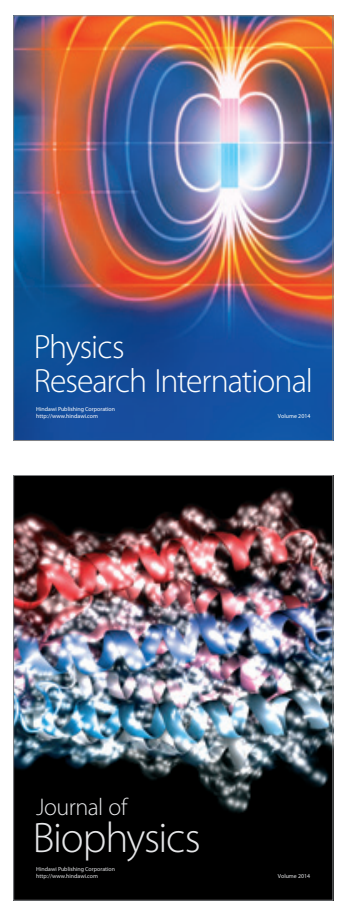
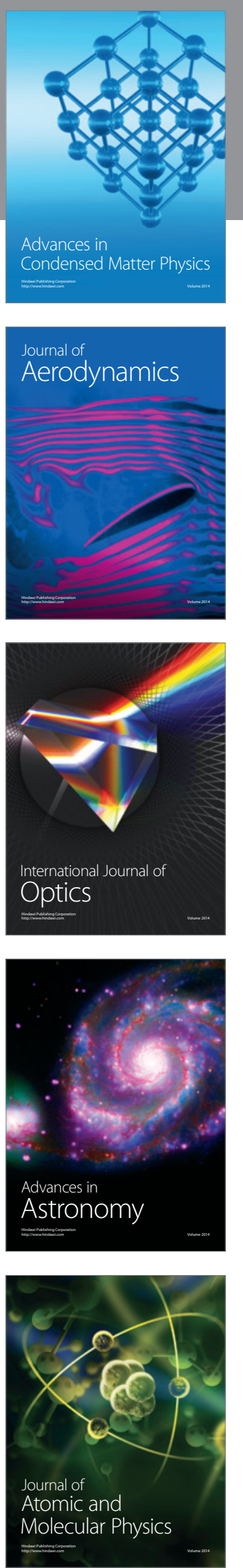